archives-ouvertes

\title{
Movements, embodiment and the emergence of decisions. Insights from insect navigation
}

\author{
Antoine Wystrach
}

\section{To cite this version:}

Antoine Wystrach. Movements, embodiment and the emergence of decisions. Insights from insect navigation. Biochemical and Biophysical Research Communications, Elsevier, 2021, 564, pp.70-77. 10.1016/j.bbrc.2021.04.114 . hal-03431220

\section{HAL Id: hal-03431220 \\ https://hal.archives-ouvertes.fr/hal-03431220}

Submitted on 16 Nov 2021

HAL is a multi-disciplinary open access archive for the deposit and dissemination of scientific research documents, whether they are published or not. The documents may come from teaching and research institutions in France or abroad, or from public or private research centers.
L'archive ouverte pluridisciplinaire HAL, est destinée au dépôt et à la diffusion de documents scientifiques de niveau recherche, publiés ou non, émanant des établissements d'enseignement et de recherche français ou étrangers, des laboratoires publics ou privés. 


\section{Biochemical and Biophysical Research Communications \\ Embodiment, movements and the emergence of decisions. Insights from insect \\ navigation. \\ --Manuscript Draft--}

\begin{tabular}{|l|l|}
\hline Manuscript Number: & BBRC-20-9695R1 \\
\hline Article Type: & SI: Rethinking Cognition \\
\hline Keywords: & $\begin{array}{l}\text { insect, cognition, minimal models, navigation, rich-club, oscillator, route following, } \\
\text { chemotaxis, embodiment }\end{array}$ \\
\hline Corresponding Author: & Antoine Wystrach \\
\hline First Author: & FRANCE \\
\hline Order of Authors: & Antoine Wystrach \\
\hline
\end{tabular}


This submission has been motivated by an invitation for the special issue: Rethinking cognition.

Cover Letter

(his submission has been motivated by an invitation for the specialissue: Rethinking cognition.
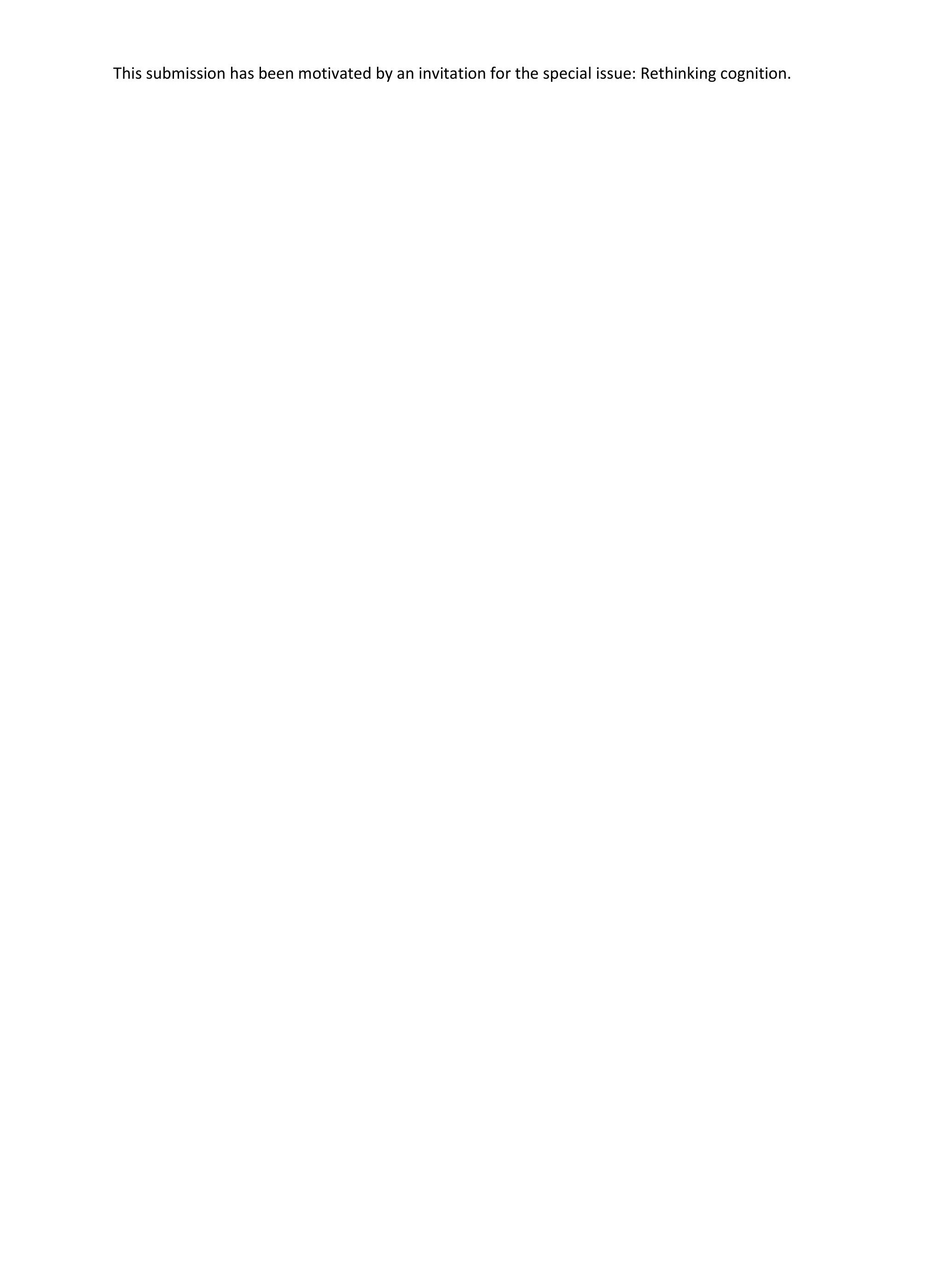


\section{Highlights}

- Movements can fundamentally transform the task for the brain.

- A same brain in different bodies or situations produces different behaviors.

- Clear-cut apparent decisions can arise without top-down control.

- A cognitive being may result from synchronization of distributed processes 
Title: Embodiment, movements and the emergence of decisions. Insights from insect navigation.

\author{
Author: Antoine Wystrach ${ }^{1}$ \\ ${ }^{1}$ Research Centre on Animal Cognition, Centre for Integrative Biology, CNRS, University of Toulouse, \\ 118 route deNarbonne, F-31062 Toulouse, Franc
}

Email: antoine.wystrach@univ-tlse3.fr

\begin{abstract}
We readily infer that animals make decisions, but what this implies is usually not clearly defined. The notion of decision making ultimately stems from human introspection, and is thus loaded with anthropomorphic assumptions. Notably, the decision is made internally, is based on information, and precedes the goal directed behaviour. Also, making a decision implies that 'something' did it, thus hints at the presence of a cognitive mind, whose existence is independent of the decision itself. This view may convey some truth, but here I take the opposite stance. Using examples from research in insect navigation, this essay highlights how apparent decisions can emerge without a brain, how actions can precede information or how novel goal directed behaviours can be implemented without neural decisions. This perspective requires us to shake off the idea that behaviour is a consequence of the brain; and embrace the concept that movements arise from - as much as participate in distributed interactions between various computational centres - including the body - that reverberate in closed-loops with their environments. From this perspective we may start to picture how a cognitive mind can be the consequence, rather than the cause, of such neural and body movements.
\end{abstract}

\title{
Embodiment in ants
}

A first approach to highlighting the interplay between brain and body is to consider examples of embodiment, where cognitive problems are outsourced to body structures and movements.

Among classic examples of embodiments is our tendency to display hand gestures when solving a spatial reasoning problem, or to mimic facial movements when judging the emotion of others. Performing such gestures does improve performance, and, in contrast, preventing them or displaying other gestures non-related to the task decreases the cognitive performance [1-3]. If someone ask you the way to the train station, stand up and free your hands before answering, your choice of words will likely be better. However, these examples illustrate merely a facilitating role to the body. Body movements can be viewed as helpful but non-essential, and may not fundamentally modify the type of cognitive process involve to solve the task. Research in ant navigation offers starker examples of embodiment, where movements transform the cognitive problem and enable novel solutions to emerge. For instance, when a foraging ant is recapitulating a well-known route using learnt visual cues [4-6], she needs first to compare the currently perceived visual scene to its memory in order to recognise whether the location is familiar. If that so, the ant must then derive information about which is the correct direction to go. A priori, this task requires complex visuo-spatial representations 
and abilities such as mental rotations or allocentric spatial reconstruction. Indeed, when engineers design robot that must follow a route, such as during the DARPA Grand Challenge race for autonomous cars [7], they resort to high accuracy sensors and impressively heavy computing power. Ants, in contrast, not only solve the same problem more robustly - they do not get lost - but do so in an apparently simpler way. Ants have low-resolution vision [8-10], their eyes are rigid and immobile, and they walk mostly forward, very rarely sideways. At first, such a reduction of sensory information and degree of freedom seem like a serious handicap. In fact, these bodily constraints are a key part of the solution. Low resolution can greatly facilitates the recognition of natural scenes - in addition to reducing memory load $[11,12]$. Second, the fact that their gaze cannot depart much from their walking direction ensure that visual input and direction of movement are profoundly linked. As a consequence, the recognition of a scene as projected on the insect eyes - that is, without the need for any cognitive spatial reconstruction - directly indicates that the body is roughly aligned in the same orientation as when the scene had been memorised in the first place [13]. In theory, all the ant needs to do is : first, memorise views while facing the route direction and second, when comes the time to retrieve the correct route direction, rotate on the spot and move forward as soon as the current view appears familiar $[14,15]$. This minimal model is supported by the fact that ants typically show such rotational scanning movements when trying to recover their route direction [16]. The trick is particularly obvious when these insects are dragging heavy items backwards: they regularly have to drop their precious load and scan around to retrieve the route direction $[17,18]$. To put it simply: physical rotations bypasses the need for mental rotations. With this embodied strategy, all that is left for the brain to do is to store and compare low resolution visual inputs encountered along the route. This simplified neural task can be readily achieved by brain neuropils called the mushroom bodies $[19,20]$, a structure that is indeed necessary for learnt visual navigation in ants [21,22]. Overall, given these bodies and movements, a few thousand neurons is all it takes to recapitulate remarkably long routes through complex environments [14,19].

Evidently, the existence of these movements do not imply that the insect lack additional, more sophisticated neural abilities $[15,23-25]$, which could be necessary for tasks requiring simulations beyond what physical movements can provide, or simply useful when producing such movements is too costly. However, through this example, one can envision how movements and body structures profoundly change the means to solve a problem. The neural circuit needed to store and compare egocentric low resolution views can be quite different -and arguably much simpler-from the one required for mental rotation or allocentric spatial reconstruction. Motor movements literally transform the information provided to the brain through sensors. After all, movements evolved before brains, and the first neurons to appear were used to coordinate muscles. This is the ground on which higher cognition is built. Scanning in ants, like human gestures when solving spatial tasks, are not just helpful tricks. They disclose a deeper, more fundamental way of functioning.

\section{Same neural mechanism, different behaviours.}

We have seen how body senses and movements can contribute to a successful behaviour, but what about a change of behaviour? Suitable changes of behaviours are typically thought to be the consequence of so-called 'decisions'; but does this necessarily implies a dedicated mental process?

When recapitulating a route home, desert ants run remarkably fast and straight $[4,5,26]$, but having arrived within close proximity of the nest, their behaviour changes drastically: they slow down and engage in convoluted searches for the nest entrance, similarly to what they do when in totally unfamiliar terrain [27-32]. 'Route following' and 'goal pinpointing' (also called 'homing') are two 
different navigational tasks. While the first demands the ability to maintain a correct direction of travel, the latter requires one to pinpoint a very specific location, often by turning around. Therefore, it initially feels intuitive that two different mechanisms are at play, and this is probably why these tasks have been typically investigated separately ('nest pinpointing': [33,34,27,35,36,28,37,38]; 'route following': [4-6,37-40] and called for different types of models [6,15,33-35,41,42]. In fact, both behaviours may well emerge from the same mechanism. The trick, revealed by behavioural observations of ants, is again about movements rather than brains. Upon leaving their nest, ants (similarly to bees and wasps [43-47]) display well-choreographed dances around the nest where they regularly turn around to pause while fixating their gaze in a specific direction, such as the nest direction [48-51]. The same happens when the insect is departing from a food source; it turns around multiple times to fixate the newly discovered goal [52-54]. Assuming that ants memorise the egocentric scene perceived during these specific goal-oriented moments is enough for a goal pinpointing behaviour to emerge from the exact same minimal 'route-following mechanism' described above $[14,55,56]$. In other words, all around the nest, the 'remembered route direction' is a constellation of memories pointing towards the nest; so that a goal-centred search emerges naturally once the end of the route is reached. The rule is always to go straight when the view is familiar, without any need for additional mechanisms, but an apparent decision to start searching emerge.

Understanding this embodied way of functioning as proved remarkably powerful in insect navigation research. Based on novel experimental and neurobiological insights, this model has been developed further to capture a wider diversity of behaviours. Notably, assuming that ants also memorise aversive views pointing away from the nest $[49,57]$, or categorise views as being to the left or right of the goal $[58,59]$ can explain why ants behave similarly close to the nest and those on unfamiliar terrain [24], how ants could home equally successfully while walking backwards [60], or how landmark information could be readily combined with other heading information in the brain [59]. Even though these revised models explain a large number of observed behaviours and are more faithful to the insects' neural circuits, the mechanism remains in essence the same. The agent does not need to decide or even 'know' whether it is close or far from its goal, yet its behaviour will still change appropriately.

The lesson from this body of work is that a suitable transition between different-looking behaviours may not necessarily result from neural top-down decisions, but can simply rely on the way the animal's body is -or has been- exposed to the environment. The learning walks displayed by naïve individuals illustrate well how this bodily factor participate to ontogeny and produce, in fine, behavioural diversity without the need to revise brain circuits.

\section{The oscillating animal}

If embodiment and environmental exposure - so-called situatedness [61]-favour the emergence of behavioural transitions within an individual, what about the more drastic differences observed across species?

Flying wasps [58] or moths [62,63], walking ants [24,64,65] or beetles [66], crawling larvae [67] or nematodes $[68,69]$, swimming vertebrates $[70,71]$ as well as moving cells $[72]$, share a strange habit: they display regular lateral oscillations along their paths, slowly alternating between left and right turns and producing a zigzag trajectory. In insects, these oscillations are rather slow, with one cycle every five seconds or so and appear to result from neural reciprocal inhibition between left and right hemisphere's pre-motor conserved brain areas $[62,73]$. The ancestral and universal nature of lateral 
oscillations suggests that they are fundamentally important across a wide range of insects with different lifestyles and body morphologies. But why?

Interestingly, when applied to ant visual navigation models, assuming that the body spontaneously generates oscillations drastically improves the efficiency of both route following [74] and homing [57]. In fact, all the agent needs to do is to modulate the amplitude of its oscillations based on the familiarity of the scene currently perceived... and it will safely go along its route and pinpoint home $[57,74]$ (figure 1A). While unfamiliar views stimulate stronger lateral oscillations, and hence changes of directions, familiar scene inhibit them and thus favour movement in the currently facing direction. The mechanism is rather trivial, but the robustness of the emerging phenomena, whether for route following and nest pinpointing, is baffling. This model, in addition to being parsimonious, gain credence as it explains how aversive and appetitive visual memories are combined and captures particular movement signatures observed in ants [24].

Remarkably, keeping the same oscillatory model but swapping the eyes for olfactory organs, and providing a gradient of odour concentration instead of a visual world, leads to a very different but well-known behaviour: chemotaxis, that is, the ability to climb up odour gradients towards the odorous food source as observed in crawling maggots [67] (figure 1). Here as well, the model - now a model for chemotaxis - can readily explain how aversive and appetitive odour memories combine, and capture particular signatures observed in maggots. Notably, the agent, just like real larvae, may switch between two apparently different strategies, one where it approaches and circles around the source as if 'orbiting', and one where it displays a dense search by triggering strong turns and repeatedly crosses over the source $[67,75]$ (figure 1B). As with the ant model, this behavioural switch does not result from a top-down neural decision, but arise from a spontaneous change in the "body movements-environment' contingency: when orbiting around the source, the larva agent experiences little changes of odour concentration, which trigger only small turns biased towards the odour side and thus sustains the orbiting activity; however when close to the odour source, the gradient tends to be sharper, increasing the probability that the agent displays sharper turns that break the orbiting trajectory. Crossing over the odour source (rather than circling around it) leads the larva to experience stronger upward and then downward changes of concentration, and thus increases the likelihood of going straight and then displaying a sharp turn after passing the odour source (figure 1B). The novel behavioural regime is thus self-sustained in a sort of positive feedback (i.e., crossing over exposes the agent to situation that favour crossing over behaviours), but given some noise, the agent may still switch back and forth between both regimes [67].

Traditionally, chemotaxis and route following are considered fundamentally different behaviours, with the former regarded as simple and primitive, while the latter viewed as more complex [76]. It is true that both behaviours look different, happen at different spatial scales, concern different sensory modalities and species, and involved different cognitive demand: learning and comparing visual scenes appears wholly more complex than following your nose. However, these apparent differences in behaviour conceal the remarkable similarity in the mechanism that produce them: the modulation of a lateral intrinsic oscillator [20] (figure 1). Turns out, the similarity goes further. Ants and maggots do recruit homologous neural circuit to achieve these different looking behaviours. In theory, a larvae does not need the mushroom bodies to display chemotaxis, but in reality, they exploit the circuitry of this neuropil to learn which odour is worth following or not $[77,78]$. It seems that larva's mushroom bodies continuously compares the currently perceived odour with previously learnt odours in a remarkably similar fashion than ants with visual scenes [20]. The strong behavioural difference emerge not so much from difference in neural circuitry, but from the difference in the movement-to-sensory relationships of vision and olfaction: oscillating paths allow for simultaneous 
change in rotation and position, but while the perception of odour concentration is sensitive to change in position rather than rotation, it is the other way around for visual input [35].

It is astonishing that meaningful but different behaviours can emerge from a same neural machinery, embodied in different sensory environments (figure 1). Over large evolutionary time scales, designs that are easily malleable may be favoured. Distributed embodied systems, when based on oscillatory movements, offer such malleability and appear to have provided a fertile ground for the evolution of novel behaviours.

\section{Do discrete behaviours mean decisions?}

When we design toy robots or video games, each specific action is typically triggered by one specific command such as 'jump', 'crouch' or 'run'; and it may feel intuitive that it should be so for animals too. One example of such discrete behaviour is the ants' actual scanning behaviour discussed earlier, where the insects suddenly stop to rotate on the spot [16]. But could such clear-cut actions arise without clear-cut decisions?

By implementing the previously mentioned oscillation models on a robot ant (i.e., a smartphone with wheels and a panoramic camera), and realising it within a natural landscape to see whether it could recapitulate a learnt route, Kodjabachev and Mangan were surprised to see their robot occasionally displaying scanning behaviours even thought there was no such command in the program [74]. The explanation is rather straightforward: in cluttered natural environments, the visual scene as perceived from the floor (at an ant's height) may become highly unfamiliar even after quite small displacements [79], and in Kodjabachev and Mangan's model, the more unfamiliar the scene, the more the robot's intrinsic oscillator is activated. Sudden perception of highly unfamiliar scenes strongly activates the oscillator and thus induce left and right turns that are so sharp that they physically override forward movement as the robot, like ants, will not drift sideways. That is, a scanning behaviour emerge. The apparent discreetness of the behaviour here does not result from a dedicated command, but from a non-linearity in the interaction between the robot and its sensory environment.

In drosophila larvae, distributed bodily interactions suffice to explains the emergence as well as the transitions between a large panels of stereotypical actions, such as forward and backward crawling motions, stops or 'head sweep' behaviours - a larva equivalent of scanning behaviours. These actions are mostly derived from the body structure itself, aided by local neural loops that trigger muscle contractions to supplement the movement [80-82]. The body dynamics at play are not at a stable equilibrium, and transition between actions result from unpredictable, chaotic dynamics in the system. As the result, the model larvae explore its environment through a diversity of behaviour and apparent decisions that matches the one observed in real larvae, despite the absence of any neural mechanisms for gathering sensory information or triggering actions [81,82]. Remarkably, real larvae with genetically silenced brain activity equally display their usual panel of behaviours in a manner and frequency that seems indistinguishable from intact larvae [83], proving that the natural transitions between discrete actions do not require brain decisions.

Obviously, signals from the brain do influence behaviour, for instance, by modulating the forward speed or the oscillations' amplitude as in the route following or chemotaxis models mentioned above. Discrete actions such as head-sweeps (or scans), stopping, or resuming forward motion after a pause can be strongly favoured by a strong or a weak signal [84], but such signals should not be seen as discrete commands because 1- they are non-essentials for the action to emerge, 2-their 
consequence remain probabilistic and 3-they operate equally at lower range in a graded manner, $[85,86]$, reflecting the continuous nature of the sensory environment. In other words, apparently clear cut behaviours do emerge without clear cut decisions.

\section{'I know therefore I do' and 'I do therefore I know'}

We have showcased how a navigating ant does not need to know whether or not it is close to its goal to engage in the correct behaviour; similarly, a larva does not even need a brain to execute a whole panel of actions. However, 'Does not need to know' does not imply 'Cannot know'. Quite the contrary, the fact that a relevant behaviour can emerge - without prior awareness - provides an additional opportunity for the system to gather knowledge from the situation, by monitoring not only the environment, but its own behavioural state.

Evidence shows that insects do monitor their own behavioural state - whether through proprioception or efference copy - to modulate various regions of their brain. For instance, whether a fly is resting still, walking or flying, will differentially activate neurons in multiple brain areas, such as motion vision neurons in the optic lobes $[87,88]$, direction sensitive neurons in the fan-shaped body of the central complex [89], or perhaps more intriguingly, dopaminergic neurons conveying positive or negative reinforcement in the mushroom bodies [90]. Not only: "I see danger therefore I'm flying away", but also: "I'm flying away therefore there might be danger". Both are probably true, and the system is surely most effective if cause and consequence are reverberating in a closed-loop (figure 2B).

In this way, movements during sequential inspections of visual patterns can provide a simple solution for bees to solve discrimination tasks or complex concept learning paradigms, eschewing the need to extract the shape or concept per se [91-93]. Similarly, human patients with visual agnosia may not recognise objects but can still perfectly adjust their grasping movements to seize them, as the action involves a different neural pathway [94]. We can see how monitoring their own movements could provide information about the size or orientation of the object, and thus transcend what is available to them through direct perception of the external world.

Perhaps a most demonstrative example of the transcendental propriety of self-monitoring is path integration. During navigation, the ability for path integration is nothing else than monitoring one's own movements to estimate its position relative to a starting position. This internal estimation, in addition to enable returning home and displaying shortcuts, can serve as a scaffold for the establishment optimal routes passing through multiple goals, a behaviour that is usually assumed to involved a mental map or knowledge about the relative position between the goal themselves $[95,96]$. Whether insects do or do not possess this knowledge is another debate $[97,98]$, but what is certain, self-monitoring can bypass the need for complex reconstruction of the world.

What difference does it make to the system whether the informative signal comes from the environment via an external sense, or from the body via an internal sense or motor copy (figure 2B)? After all, the body can be viewed as a perceptual environment, one that can be particularly well controlled. 


\section{Is there a ghost in the machine?}

The works presented here point at a distributed and dynamic nature of behavioural control (figure 2B), which contrast strongly with our intuitive sense of a cognitive being, in the sense of a higher awareness - or ghost in the machine - resulting from a global integration of information and producing top-down decision (figure $2 \mathrm{~A}$ ). However, both views are not necessarily mutually exclusive.

Perhaps a promising research for tackling the existence of such top-down decision is the study of attention-like processes, for which a 'selection' in the brain must precedes behavioural choices. There is strong evidence for such processes in insects $[99,100]$. Insects can 'focus' on specific cues and 'disregard' others not only based on the current sensory cues themselves (which can be achieved through neural filtering and winner-takes-all competition, forming a so-called bottom-up control of attention) or their own behavioural state (previous paragraph), but also based on their past experiences and current internal state. For instance, a fly will recall olfactory memories and track an odour previously associated with food only if it is hungry [101]. Similarly, a larva will not bother recalling olfactory memories associated with sugar, if sugar is already present in the environment [102]. Likewise, depending on its motivational state, an ant will recall either food-ward or homeward visual memories and disregard the other $[103,104]$.

One key question is whether such 'internal' decisions result from local and specific gating mechanisms or from a global information integration. The latter could be implemented in brain-wide networks of highly connected neurons such as the so-called 'rich club', which we observe in human [105] but also animals including insects or nematodes' connectome [106-108]. However, evidence in insects rather support the former. For instance, neurons releasing the neuropeptide $F$, which convey specific homeostatic information such as lack of a given nutrient, modulate equally nutrient-specific dopaminergic neurons, thereby directly gating the learning and/or expression of the memories associated with this specific nutrient need $[101,109]$. Some internal modulations have less specific targets: hormones and giant neurons innervating multiple regions can diffuse information throughout the brain to modulate behaviour [110-113]. But here also the information transmitted is more direct and situation specific than the product of a brain-wide like integration process; and the consequence on behaviour is more probabilistic than the result of a clear cut decision.

But then, what would the role of 'rich club' like brain-wide networks be? Instead of - or in addition to - 'integration', these networks may be key for 'synchronisation' of neural activity across far-flung regions $[105,107,108]$, thereby imposing the coherence underlying attention [114] at a larger scale. Rather than decision centres, perhaps such networks can be viewed as blind orchestrators, crystallising the many local and specific 'decisions' achieved in different parts of the brain-bodyenvironment system into a globally co-ordinated, and thus meaningful, activity (figure 2B). This neural resonance may well support a rich subjective experience, and hence, a cognitive being. If that is the case, the cognitive being would be more the consequence of a democratic poll than a monarch imposing decisions.

\section{Conclusion}

The minimal models of insect navigation presented here illustrate the power of dynamic and closedloop processes, where behaviours arise from distributed interactions between brain, body, movements and environment, where the distinctions between internal or external source of information is blurred, and the notions of cause and consequence are supplanted by the one of emergence. These processes enable clear-cut actions and appropriate shift in behaviours to happen despite worryingly simple neural mechanisms, far removed from what we could call decisions. As a 
corollary, they provide insight into how novel behaviours can arise along ontogeny and evolution without much change in the underlying mechanisms.

The motivation behind this approach is not to assume that insects are non-cognitive beings, but to seek the most parsimonious explanation behind these apparently complex phenomena, while departing as much as possible from our anthropomorphic intuitions [115]. However, one should keep in mind that it is our models that have simple brains, not the insects; and this approach is not mutually exclusive to a more cognitive view. On the contrary, the distributed mechanisms presented here form a formidable basis on which higher level decision-making could operate, as they produce meaningful behaviour that can be readily modulated given minimal variation in neural activity. Also, such distributed systems might need to be globally synchronised to be operational on a given task. Rather than a ghost in the machine taking decisions, perhaps it is the need for such a synchronisation, implemented through richly connected neural networks imposing a system-wide resonance, that may provoke what we could call a cognitive being.

\section{Figure legends}

Figure 1. One neural mechanism, multiple behaviours. A variety of functionally relevant behaviours can arise from a same algorithm based on an intrinsic oscillator embodied in different sensorymovement contingency. A) Given panoramic visual scene as input, the algorithm (left) will result in route following or nest pinpointing behaviours depending on the movements that were achieved during previous learning stage. (Red dots: overall path taken by the agent in a realistic reconstructed visual world [116], as modelled in [57]). B) Given olfactory receptors able to detect change in odour concentration, the same neural algorithm (left) can produce two different chemotaxis behavioural regimes that self-sustain purely because of body movements-environment contingency. (blue dot: odour source; blue lines: isoclines of odour concentration; dark dots: overall path taken by the agent, as modelled in [67]). A,B) Both models can involve the same circuitry based on the insect's mushroom body [20]. Changing the nature of the sensory input suffice to switch from visual navigation to chemotaxis behaviours.

\section{Figure 2. Two non-mutually exclusive views of the flow of information underlying an organism's} behaviour. A) The first scheme highlights integration of external world information and subsequent top-down decisions. 'Rich-club' brain-wide neural networks may achieve a global integration of information to support a cognitive being that actively produce decisions (green). B) The second scheme emphasizes parallel and reverberating closed-loop processes, body/environment interactions as well as the distributed and self-emerging nature of decisions. A cognitive being may arise from a need for overall coherence of the system through synchronisation (and hence selection) of process activity, which could be achieved by 'rich-club' brain wide networks (in green).

\section{Acknowledgments}

I am grateful to Patrick Shultheiss and Cody Freas for polishing the writing of a previous version of this manuscript, as well as one anonymous reviewer for his helpful suggestions.

\section{Funding}

This work was funded by the European Research Council (ERCstg: EMERG-ANT 759817).

\section{References}

[1] P.M. Niedenthal, Embodying Emotion, Science. 316 (2007) 1002-1005. https://doi.org/10.1126/science.1136930. 
[2] D. Moreau, Constraining movement alters the recruitment of motor processes in mental rotation, Exp Brain Res. 224 (2013) 447-454. https://doi.org/10.1007/s00221-012-3324-0.

[3] A. Wohlschläger, A. Wohlschläger, Mental and manual rotation., Journal of Experimental Psychology: Human Perception and Performance. 24 (1998) 397.

[4] M. Kohler, R. Wehner, Idiosyncratic route-based memories in desert ants, Melophorus bagoti: How do they interact with path-integration vectors?, Neurobiology of Learning and Memory. 83 (2005) 1-12.

[5] M. Mangan, B. Webb, Spontaneous formation of multiple routes in individual desert ants (Cataglyphis velox), Behavioral Ecology. 23 (2012) 944-954.

[6] A. Wystrach, S. Schwarz, P. Schultheiss, G. Beugnon, K. Cheng, Views, landmarks, and routes: how do desert ants negotiate an obstacle course?, Journal of Comparative Physiology ANeuroethology Sensory Neural and Behavioral Physiology. 197 (2011) 167-179. https://doi.org/10.1007/s00359-010-0597-2.

[7] G. Seetharaman, A. Lakhotia, E.P. Blasch, Unmanned vehicles come of age: The DARPA grand challenge, Computer. 39 (2006) 26-29.

[8] S. Schwarz, A. Narendra, J. Zeil, The properties of the visual system in the Australian desert ant Melophorus bagoti, Arthropod Structure \& Development. 40 (2011) 128-134.

[9] C.P.E. Zollikofer, R. Wehner, T. Fukushi, Optical Scaling in Conspecific Cataglyphis Ants, Journal of Experimental Biology. 198 (1995) 1637-1646.

[10] Y. Ogawa, L.A. Ryan, R. Palavalli-Nettimi, O. Seeger, N.S. Hart, A. Narendra, Spatial resolving power and contrast sensitivity are adapted for ambient light conditions in Australian Myrmecia ants, Frontiers in Ecology and Evolution. 7 (2019) 18.

[11] P. Graham, A. Philippides, Vision for navigation: what can we learn from ants?, Arthropod Structure \& Development. 46 (2017) 718-722.

[12] A. Wystrach, A. Dewar, A. Philippides, P. Graham, How do field of view and resolution affect the information content of panoramic scenes for visual navigation? A computational investigation, Journal of Comparative Physiology A. 202 (2016) 87-95.

[13] J. Zeil, Visual homing: an insect perspective, Current Opinion in Neurobiology. 22 (2012) 285293. http://dx.doi.org/10.1016/j.conb.2011.12.008.

[14] B. Baddeley, P. Graham, P. Husbands, A. Philippides, A model of ant route navigation driven by scene familiarity, PLoS Comput Biol. 8 (2012) e1002336. https://doi.org/10.1371/journal.pcbi.1002336.

[15] A. Wystrach, G. Beugnon, K. Cheng, Ants might use different view-matching strategies on and off the route, The Journal of Experimental Biology. 215 (2012) 44-55. https://doi.org/10.1242/jeb.059584.

[16] A. Wystrach, A. Philippides, A. Aurejac, K. Cheng, P. Graham, Visual scanning behaviours and their role in the navigation of the Australian desert ant Melophorus bagoti, Journal of Comparative Physiology A. (2014) 1-12.

[17] S.E. Pfeffer, M. Wittlinger, How to find home backwards? Navigation during rearward homing of Cataglyphis fortis desert ants, Journal of Experimental Biology. 219 (2016) 2119-2126.

[18] S. Schwarz, M. Mangan, J. Zeil, B. Webb, A. Wystrach, How Ants Use Vision When Homing Backward, Current Biology. 27 (2017) 401-407. https://doi.org/10.1016/j.cub.2016.12.019.

[19] P. Ardin, F. Peng, M. Mangan, K. Lagogiannis, B. Webb, Using an Insect Mushroom Body Circuit to Encode Route Memory in Complex Natural Environments, PLOS Computational Biology. 12 (2016) e1004683. https://doi.org/10.1371/journal.pcbi.1004683.

[20] B. Webb, A. Wystrach, Neural mechanisms of insect navigation, Current Opinion in Insect Science. 15 (2016) 27-39. https://doi.org/10.1016/j.cois.2016.02.011.

[21] J.F. Kamhi, A.B. Barron, A. Narendra, Vertical lobes of the mushroom bodies are essential for view-based navigation in Australian Myrmecia ants, Current Biology. 30 (2020) 3432-3437.

[22] C. Buehlmann, B. Wozniak, R. Goulard, B. Webb, P. Graham, J.E. Niven, Mushroom Bodies Are Required for Learned Visual Navigation, but Not for Innate Visual Behavior, in Ants, Current Biology. (2020). https://doi.org/10.1016/j.cub.2020.07.013. 
[23] Stone Thomas, Mangan Michael, Wystrach Antoine, Webb Barbara, Rotation invariant visual processing for spatial memory in insects, Interface Focus. 8 (2018) 20180010.

https://doi.org/10.1098/rsfs.2018.0010.

[24] T. Murray, Z. Kocsi, H. Dahmen, A. Narendra, F.L. Möel, A. Wystrach, J. Zeil, The role of attractive and repellent scene memories in ant homing (Myrmecia croslandi), Journal of Experimental Biology. (2019). https://doi.org/10.1242/jeb.210021.

[25] T. Stone, B. Webb, A. Adden, N.B. Weddig, A. Honkanen, R. Templin, W. Wcislo, L. Scimeca, E. Warrant, S. Heinze, An Anatomically Constrained Model for Path Integration in the Bee Brain, Current Biology. 27 (2017) 3069-3085.e11. https://doi.org/10.1016/j.cub.2017.08.052.

[26] S.E. Pfeffer, V.L. Wahl, M. Wittlinger, H. Wolf, High-speed locomotion in the Saharan silver ant, Cataglyphis bombycina, Journal of Experimental Biology. 222 (2019) jeb198705.

[27] R. Wehner, B. Michel, P. Antonsen, Visual navigation in insects: Coupling of egocentric and geocentric information, Journal of Experimental Biology. 199 (1996) 129-140.

[28] P. Schultheiss, A. Wystrach, E.L.G. Legge, K. Cheng, Information content of visual scenes influences systematic search of desert ants, The Journal of Experimental Biology. 216 (2013) 742-749. https://doi.org/10.1242/jeb.075077.

[29] C. Buehlmann, A.S.D. Fernandes, P. Graham, The interaction of path integration and terrestrial visual cues in navigating desert ants: what can we learn from path characteristics?, Journal of Experimental Biology. 221 (2018) jeb167304. https://doi.org/10.1242/jeb.167304.

[30] P. Schultheiss, K. Cheng, Finding the nest: inbound searching behaviour in the Australian desert ant, Melophorus bagoti, Animal Behaviour. 81 (2011) 1031-1038.

[31] T. Merkle, M. Knaden, R. Wehner, Uncertainty about nest position influences systematic search strategies in desert ants, Journal of Experimental Biology. 209 (2006) 3545-3549.

[32] M. Müller, R. Wehner, The Hidden Spiral - Systematic Search and Path Integration in Desert Ants, Cataglyphis-Fortis, Journal of Comparative Physiology A-Sensory Neural and Behavioral Physiology. 175 (1994) 525-530.

[33] R. Wehner, F. Räber, Visual spatial memory in desert ants, Cataglyphis bicolor (Hymenoptera: Formicidae), Experientia. 35 (1979) 1569 \pm 1571.

[34] B.A. Cartwright, T.S. Collett, Landmark learning in bees - experiments and models, Journal of Comparative Physiology. 151 (1983) 521-543.

[35] J. Zeil, M.I. Hofmann, J.S. Chahl, Catchment areas of panoramic snapshots in outdoor scenes, Journal of the Optical Society of America A-Optics Image Science and Vision. 20 (2003) 450469.

[36] L. Dittmar, W. Sturzl, E. Baird, N. Boeddeker, M. Egelhaaf, Goal seeking in honeybees: matching of optic flow snapshots?, Journal of Experimental Biology. 213 (2010) 2913-2923. https://doi.org/10.1242/jeb.043737.

[37] T.S. Collett, Insect navigation en route to the goal: Multiple strategies for the use of landmarks, Journal of Experimental Biology. 199 (1996) 227-235.

[38] D. Macquart, L. Garnier, M. Combe, G. Beugnon, Ant navigation en route to the goal: signature routes facilitate way-finding of Gigantiops destructor, Journal of Comparative Physiology ANeuroethology Sensory Neural and Behavioral Physiology. 192 (2006) 221-234.

[39] T.S. Collett, P. Graham, V. Durier, Route learning by insects, Current Opinion in Neurobiology. 13 (2003) 718-725.

[40] D.D. Lent, P. Graham, T.S. Collett, A Motor Component to the Memories of Habitual Foraging Routes in Wood Ants?, Current Biology. 19 (2009) 115-121. https://doi.org/10.1016/j.cub.2008.11.060.

[41] R. Möller, A. Vardy, Local visual homing by matched-filter descent in image distances, Biological Cybernetics. 95 (2006) 413-430.

[42] M. Collett, How desert ants use a visual landmark for guidance along a habitual route, Proceedings of the National Academy of Sciences of the United States of America. 107 (2010) 11638-11643. https://doi.org/10.1073/pnas.1001401107. 
[43] J. Zeil, Orientation flights of solitary wasps (Cerceris, Sphecidae, Hymenoptera) .1. Description of flight, Journal of Comparative Physiology A-Sensory Neural and Behavioral Physiology. 172 (1993) 189-205.

[44] A. Philippides, N.H. de Ibarra, O. Riabinina, T.S. Collett, Bumblebee calligraphy: the design and control of flight motifs in the learning and return flights of Bombus terrestris, The Journal of Experimental Biology. 216 (2013) 1093-1104. https://doi.org/10.1242/jeb.081455.

[45] J. Zeil, A. Kelber, R. Voss, Structure and function of learning flights in bees and wasps, Journal of Experimental Biology. 199 (1996) 245-252.

[46] N. Tinbergen, W. Kruyt, Über die Orientierung des Bienenwolfes (Philanthus triangulum Fabr.), Zeitshrift Fuer Vergleichende Physiologie. 25 (1938) 292-334. https://doi.org/10.1007/BF00339640.

[47] M. Lehrer, Bees which turn back and look, Naturwissenschaften. 78 (1991) 274-276.

[48] M. Müller, R. Wehner, Path Integration Provides a Scaffold for Landmark Learning in Desert Ants, Current Biology. 20 (2010) 1368-1371. https://doi.org/10.1016/j.cub.2010.06.035.

[49] P. Jayatilaka, T. Murray, A. Narendra, J. Zeil, The choreography of learning walks in the Australian jack jumper ant Myrmecia croslandi, Journal of Experimental Biology. 221 (2018) jeb185306.

[50] P.N. Fleischmann, W. Rössler, R. Wehner, Early foraging life: spatial and temporal aspects of landmark learning in the ant Cataglyphis noda, Journal of Comparative Physiology A. 204 (2018) 579-592.

[51] J. Zeil, P.N. Fleischmann, The learning walks of ants (Hymenoptera: Formicidae), (2019).

[52] D.J. Nicholson, S.P.D. Judd, B.A. Cartwright, T.S. Collett, Learning walks and landmark guidance in wood ants (Formica rufa), Journal of Experimental Biology. 202 (1999) 1831-1838.

[53] S.P.D. Judd, T.S. Collett, Multiple stored views and landmark guidance in ants, Nature. 392 (1998) 710-714.

[54] C. Wei, S. Rafalko, F. Dyer, Deciding to learn: modulation of learning flights in honeybees, Apis mellifera, Journal of Comparative Physiology A. 188 (2002) 725-737.

[55] A. Wystrach, M. Mangan, A. Philippides, P. Graham, Snapshots in ants? New interpretations of paradigmatic experiments, The Journal of Experimental Biology. 216 (2013) 1766-1770. https://doi.org/10.1242/jeb.082941.

[56] P. Graham, A. Philippides, B. Baddeley, Animal cognition: multi-modal interactions in ant learning, Current Biology. 20 (2010) R639-R640. https://doi.org/10.1016/j.cub.2010.06.018.

[57] F.L. Möel, A. Wystrach, Opponent processes in visual memories: A model of attraction and repulsion in navigating insects' mushroom bodies, PLOS Computational Biology. 16 (2020) e1007631. https://doi.org/10.1371/journal.pcbi.1007631.

[58] W. Stürzl, J. Zeil, N. Boeddeker, J.M. Hemmi, How Wasps Acquire and Use Views for Homing, Current Biology. 26 (2016) 470-482. https://doi.org/10.1016/j.cub.2015.12.052.

[59] A. Wystrach, F. Le Moel, L. Clement, S. Schwarz, A lateralised design for the interaction of visual memories and heading representations in navigating ants, BioRxiv. (2020).

[60] S. Schwarz, L. Clement, E. Gkanias, A. Wystrach, How do backward-walking ants (Cataglyphis velox) cope with navigational uncertainty?, Animal Behaviour. 164 (2020) 133-142.

[61] R.D. Beer, 6 - The Dynamics of Brain-Body-Environment Systems: A Status Report, in: P. Calvo, A. Gomila (Eds.), Handbook of Cognitive Science, Elsevier, San Diego, 2008: pp. 99-120. https://doi.org/10.1016/B978-0-08-046616-3.00006-2.

[62] S. Namiki, R. Kanzaki, The neurobiological basis of orientation in insects: insights from the silkmoth mating dance, Current Opinion in Insect Science. 15 (2016) 16-26. https://doi.org/10.1016/j.cois.2016.02.009.

[63] L.P.S. Kuenen, T.C. Baker, A non-anemotactic mechanism used in pheromone source location by flying moths, Physiological Entomology. 8 (1983) 277-289.

[64] D.D. Lent, P. Graham, T.S. Collett, Phase-Dependent Visual Control of the Zigzag Paths of Navigating Wood Ants, Current Biology. 23 (2013) 2393-2399.

http://dx.doi.org/10.1016/j.cub.2013.10.014. 
[65] W. Hangartner, Spezifität und inaktivierung des spurpheromons von Lasius fuliginosus Latr. und orientierung der arbeiterinnen im duftfeld, Zeitschrift Für Vergleichende Physiologie. 57 (1967) 103-136.

[66] U. Lönnendonker, Dynamic Properties of Orientation to a Visually Fixated Target by Walking Colorado Beetles, Journal of Experimental Biology. 158 (1991) 149-164.

[67] A. Wystrach, K. Lagogiannis, B. Webb, Continuous lateral oscillations as a core mechanism for taxis in Drosophila larvae, Elife. 5 (2016) e15504.

[68] Y. lino, K. Yoshida, Parallel use of two behavioral mechanisms for chemotaxis in Caenorhabditis elegans, The Journal of Neuroscience. 29 (2009) 5370-5380.

[69] E.J. Izquierdo, S.R. Lockery, Evolution and Analysis of Minimal Neural Circuits for Klinotaxis in Caenorhabditis elegans, The Journal of Neuroscience. 30 (2010) 12908-12917. https://doi.org/10.1523/jneurosci.2606-10.2010.

[70] S. Wolf, A.M. Dubreuil, T. Bertoni, U.L. Böhm, V. Bormuth, R. Candelier, S. Karpenko, D.G. Hildebrand, I.H. Bianco, R. Monasson, Sensorimotor computation underlying phototaxis in zebrafish, Nature Communications. 8 (2017) 1-12.

[71] A. Lansner, Realistic modeling of burst generation and swimming in lamprey, Neurons, Networks, and Motor Behavior. (1997) 165-171.

[72] T.D. Yang, J.-S. Park, Y. Choi, W. Choi, T.-W. Ko, K.J. Lee, Zigzag turning preference of freely crawling cells, PLoS ONE. 6 (2011) e20255.

[73] F. Steinbeck, A. Adden, P. Graham, Connecting brain to behaviour: a role for general purpose steering circuits in insect orientation?, Journal of Experimental Biology. 223 (2020). https://doi.org/10.1242/jeb.212332.

[74] A. Kodzhabashev, M. Mangan, Route Following Without Scanning, in: Biomimetic and Biohybrid Systems, Springer, 2015: pp. 199-210.

[75] A. Gomez-Marin, G.J. Stephens, M. Louis, Active sampling and decision making in Drosophila chemotaxis, Nature Communications. 2 (2011) 441.

[76] J. Wiener, S.J. Shettleworth, V.P. Bingman, K. Cheng, S. Healy, L.F. Jacobs, K. Jeffrey, H.A. Mallot, R. Menzel, N.S. Newcombe, Animal navigation. A synthesis, in: R. Menzel, J. Fischer (Eds.), Animal Thinking. Contemporary Issues of Comparative Cognition, MIT Press, Cambirdge, Massachusetts, 2011: pp. 51-78.

[77] K. Eichler, F. Li, A. Litwin-Kumar, Y. Park, I. Andrade, C.M. Schneider-Mizell, T. Saumweber, A. Huser, C. Eschbach, B. Gerber, R.D. Fetter, J.W. Truman, C.E. Priebe, L.F. Abbott, A.S. Thum, M. Zlatic, A. Cardona, The complete connectome of a learning and memory centre in an insect brain, Nature. 548 (2017) 175-182. https://doi.org/10.1038/nature23455.

[78] T. Saumweber, A. Rohwedder, M. Schleyer, K. Eichler, Y. Chen, Y. Aso, A. Cardona, C. Eschbach, O. Kobler, A. Voigt, A. Durairaja, N. Mancini, M. Zlatic, J.W. Truman, A.S. Thum, B. Gerber, Functional architecture of reward learning in mushroom body extrinsic neurons of larval Drosophila, Nature Communications. 9 (2018) 1104. https://doi.org/10.1038/s41467018-03130-1.

[79] A. Philippides, B. Baddeley, K. Cheng, P. Graham, How might ants use panoramic views for route navigation?, Journal of Experimental Biology. 214 (2011) 445-451. https://doi.org/10.1242/jeb.046755.

[80] D. Ross, K. Lagogiannis, B. Webb, A model of larval biomechanics reveals exploitable passive properties for efficient locomotion, in: Conference on Biomimetic and Biohybrid Systems, Springer, 2015: pp. 1-12.

[81] J. Loveless, B. Webb, A Neuromechanical Model of Larval Chemotaxis, Integr Comp Biol. 58 (2018) 906-914. https://doi.org/10.1093/icb/icy094.

[82] J. Loveless, K. Lagogiannis, B. Webb, Modelling the mechanics of exploration in larval Drosophila, PLoS Computational Biology. 15 (2019) e1006635.

[83] J. Berni, S.R. Pulver, L.C. Griffith, M. Bate, Autonomous circuitry for substrate exploration in freely moving Drosophila larvae, Current Biology. 22 (2012) 1861-1870. 
[84] I. Tastekin, A. Khandelwal, D. Tadres, N.D. Fessner, J.W. Truman, M. Zlatic, A. Cardona, M. Louis, Sensorimotor pathway controlling stopping behavior during chemotaxis in the Drosophila melanogaster larva, ELife. 7 (2018) e38740. https://doi.org/10.7554/eLife.38740.

[85] A. Gomez-Marin, M. Louis, Multilevel control of run orientation in Drosophila larval chemotaxis, Frontiers in Behavioral Neuroscience. 8 (2014) 38. https://doi.org/10.3389/fnbeh.2014.00038.

[86] S. Ohashi, T. Morimoto, Y. Suzuki, H. Miyakawa, T. Aonishi, A novel behavioral strategy, continuous biased running, during chemotaxis in Drosophila larvae, Neuroscience Letters. 570 (2014) 10-15.

[87] M.E. Chiappe, J.D. Seelig, M.B. Reiser, V. Jayaraman, Walking Modulates Speed Sensitivity in Drosophila Motion Vision, Current Biology. 20 (2010) 1470-1475. https://doi.org/10.1016/j.cub.2010.06.072.

[88] G. Maimon, A.D. Straw, M.H. Dickinson, Active flight increases the gain of visual motion processing in Drosophila, Nature Neuroscience. 13 (2010) 393-399.

[89] P.T. Weir, M.H. Dickinson, Functional divisions for visual processing in the central brain of flying Drosophila, PNAS. 112 (2015) E5523-E5532. https://doi.org/10.1073/pnas.1514415112.

[90] R. Cohn, I. Morantte, V. Ruta, Coordinated and Compartmentalized Neuromodulation Shapes Sensory Processing in Drosophila, Cell. 163 (2015) 1742-1755. https://doi.org/10.1016/j.cell.2015.11.019.

[91] M. Guiraud, M. Roper, L. Chittka, High-speed videography reveals how honeybees can turn a spatial concept learning task into a simple discrimination task by stereotyped flight movements and sequential inspection of pattern elements, Frontiers in Psychology. 9 (2018) 1347.

[92] F. Le Moël, S. Schwarz, M. Lihoreau, A. Wystrach, A killjoy perspective on object representation by bumblebees, (2020).

[93] V. Vasas, L. Chittka, Insect-inspired sequential inspection strategy enables an artificial network of four neurons to estimate numerosity, IScience. 11 (2019) 85-92.

[94] D. Milner, M. Goodale, The visual brain in action, OUP Oxford, 2006.

[95] F. Le Moël, T. Stone, M. Lihoreau, A. Wystrach, B. Webb, The Central Complex as a Potential Substrate for Vector Based Navigation, Front. Psychol. 10 (2019). https://doi.org/10.3389/fpsyg.2019.00690.

[96] H. Cruse, R. Wehner, No need for a cognitive map: decentralized memory for insect navigation, Plos Computational Biology. 7 (2011). https://doi.org/10.1371/journal.pcbi.1002009.

[97] J.F. Cheeseman, C.D. Millar, U. Greggers, K. Lehmann, M.D. Pawley, C.R. Gallistel, G.R. Warman, R. Menzel, Way-finding in displaced clock-shifted bees proves bees use a cognitive map, Proceedings of the National Academy of Sciences. 111 (2014) 8949-8954.

[98] A. Cheung, M. Collett, T.S. Collett, A. Dewar, F. Dyer, P. Graham, M. Mangan, A. Narendra, A. Philippides, W. Stürzl, Still no convincing evidence for cognitive map use by honeybees, Proceedings of the National Academy of Sciences. 111 (2014) E4396-E4397.

[99] V. Nityananda, Attention-like processes in insects, Proceedings of the Royal Society B: Biological Sciences. 283 (2016) 20161986. https://doi.org/10.1098/rspb.2016.1986.

[100] B.L. de Bivort, B. van Swinderen, Evidence for selective attention in the insect brain, Current Opinion in Insect Science. 15 (2016) 9-15. https://doi.org/10.1016/j.cois.2016.02.007.

[101] M.J. Krashes, S. DasGupta, A. Vreede, B. White, J.D. Armstrong, S. Waddell, A neural circuit mechanism integrating motivational state with memory expression in Drosophila, Cell. 139 (2009) 416-427. https://doi.org/10.1016/j.cell.2009.08.035.

[102] M. Schleyer, S.F. Reid, E. Pamir, T. Saumweber, E. Paisios, A. Davies, B. Gerber, M. Louis, The impact of odor-reward memory on chemotaxis in larval Drosophila, Learning \& Memory. 22 (2015) 267-277. https://doi.org/10.1101/lm.037978.114.

[103] R.A. Harris, N.H. Hempel de Ibarra, P. Graham, T.S. Collett, Ant navigation - Priming of visual route memories, Nature. 438 (2005) 302-302. 
[104] R. Wehner, M. Boyer, F. Loertscher, S. Sommer, U. Menzi, Ant navigation: One-way routes rather than maps, Current Biology. 16 (2006) 75-79.

[105] M.P. van den Heuvel, O. Sporns, Rich-Club Organization of the Human Connectome, J. Neurosci. 31 (2011) 15775-15786. https://doi.org/10.1523/JNEUROSCI.3539-11.2011.

[106] A. Griffa, M.P. Van den Heuvel, Rich-club neurocircuitry: function, evolution, and vulnerability, Dialogues Clin Neurosci. 20 (2018) 121-132.

[107] E.K. Towlson, P.E. Vértes, S.E. Ahnert, W.R. Schafer, E.T. Bullmore, The Rich Club of the C. elegans Neuronal Connectome, J. Neurosci. 33 (2013) 6380-6387. https://doi.org/10.1523/JNEUROSCI.3784-12.2013.

[108] C.-T. Shih, O. Sporns, S.-L. Yuan, T.-S. Su, Y.-J. Lin, C.-C. Chuang, T.-Y. Wang, C.-C. Lo, R.J. Greenspan, A.-S. Chiang, Connectomics-Based Analysis of Information Flow in the Drosophila Brain, Current Biology. 25 (2015) 1249-1258. https://doi.org/10.1016/j.cub.2015.03.021.

[109] M. Schleyer, A. Weiglein, J. Thoener, M. Strauch, V. Hartenstein, M.K. Weigelt, S. Schuller, T. Saumweber, K. Eichler, A. Rohwedder, D. Merhof, M. Zlatic, A.S. Thum, B. Gerber, Identification of Dopaminergic Neurons That Can Both Establish Associative Memory and Acutely Terminate Its Behavioral Expression, J. Neurosci. 40 (2020) 5990-6006. https://doi.org/10.1523/JNEUROSCI.0290-20.2020.

[110] A.M. Dacks, T.A. Christensen, H.-J. Agricola, L. Wollweber, J.G. Hildebrand, Octopamineimmunoreactive neurons in the brain and subesophageal ganglion of the hawkmoth Manduca sexta, Journal of Comparative Neurology. 488 (2005) 255-268. https://doi.org/10.1002/cne.20556.

[111] T. Roeder, Octopamine in invertebrates, Progress in Neurobiology. 59 (1999) 533-561. https://doi.org/10.1016/S0301-0082(99)00016-7.

[112] M. Hammer, R. Menzel, Learning and memory in the honeybee, Journal of Neuroscience. 15 (1995) 1617-1630.

[113] C.J. Perry, L. Baciadonna, L. Chittka, Unexpected rewards induce dopamine-dependent positive emotion-like state changes in bumblebees, Science. 353 (2016) 1529-1531.

[114] P. Fries, Rhythms for Cognition: Communication through Coherence, Neuron. 88 (2015) 220235. https://doi.org/10.1016/j.neuron.2015.09.034.

[115] A. Wystrach, P. Graham, What can we learn from studies of insect navigation?, Animal Behaviour. 84 (2012) 13-20. https://doi.org/10.1016/j.anbehav.2012.04.017.

[116] W. Stürzl, I. Grixa, E. Mair, A. Narendra, J. Zeil, Three-dimensional models of natural environments and the mapping of navigational information, Journal of Comparative Physiology A. 201 (2015) 563-584. 
Eigure 2

Environment $\rightarrow$
Click here to

$\underline{\underline{ }}$

access/downdoad;Figure;Fig Sensors

Computation

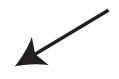

Action $\longleftarrow$ Motor


\section{Integration}

decision

cognitive being?

cognitive being?

Synchronisation

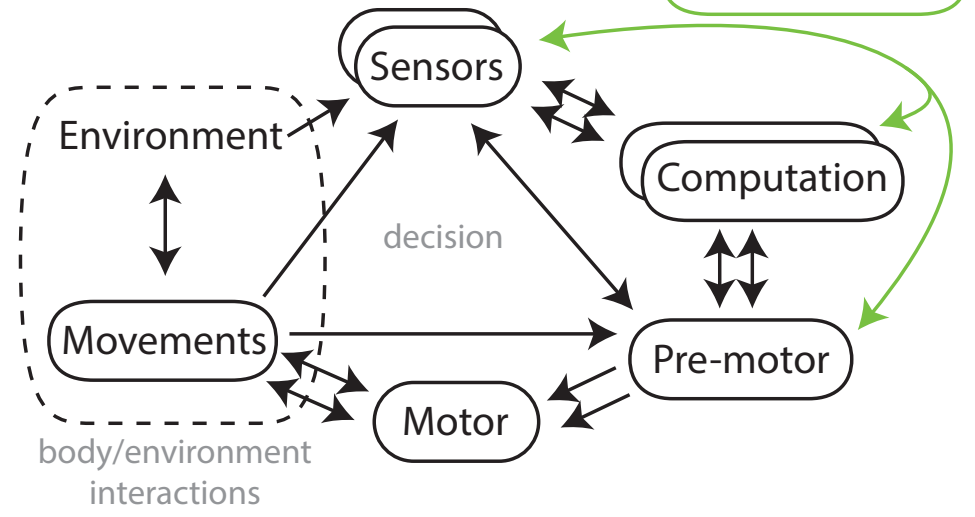




\section{Figure-1}

A Visual navigation

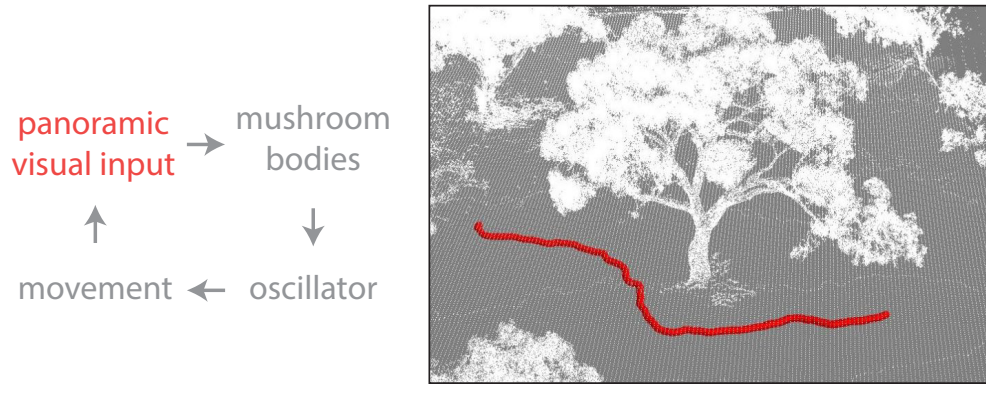

Route following behaviour

Cliek here to aceesstelowntoad;Figure; Figure-1.pdf *

Goal pinpointing behaviour

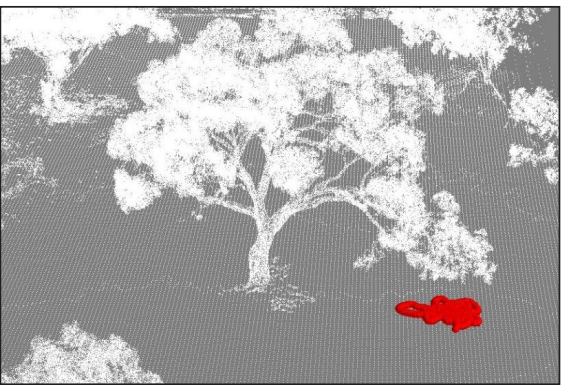

different ontogeny

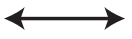



$\pi$

same

algorithm

\section{B Chemotaxis}

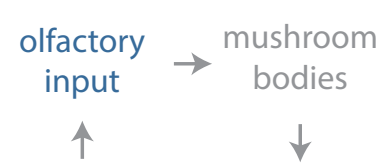

movement $\leftarrow$ oscillator
Orbiting behaviour

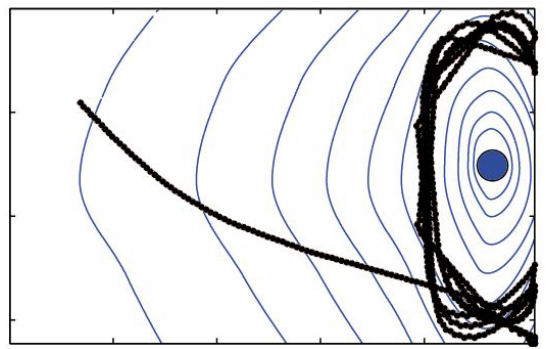

different body/environment contingency



Crossing-over behaviour

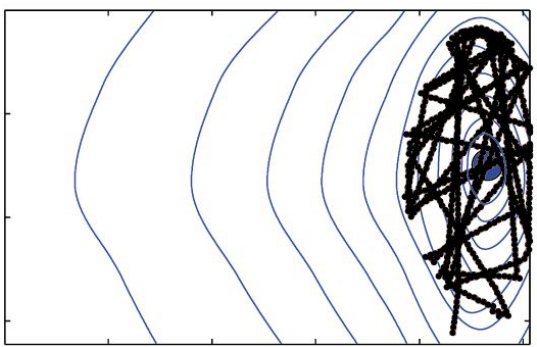


Visual navigation 
Visual navigation 
Visual navigation 
Visual navigation 
Conflict of Interest

The author declares no conflict of interest

\section{Conflict of Interest}

The author declares no conflict of interest

st

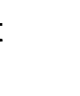

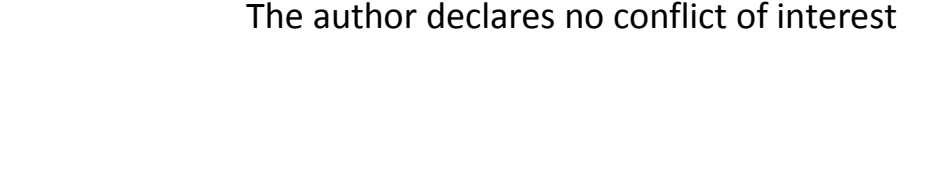

(n)

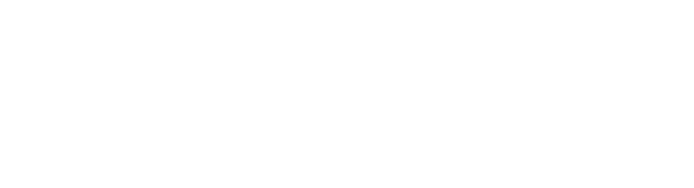

ond

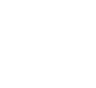

(n)
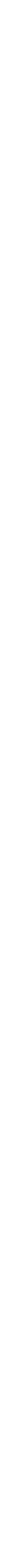